\title{
LA PARTICIPACIÓN CIUDADANA EN LA PRESTACIÓN DE LOS SERVICIOS PÚBLICOS. EL SUPUESTO DE LAS COOPERATIVAS DE UTILIDAD PÚBLICA EN LA COMUNIDAD AUTÓNOMA DEL PAÍS VASCO
}

\author{
POR \\ Vega María ARNÁEZ ARCE ${ }^{1}$
}

\section{RESUMEN}

En el presente trabajo se aborda una de las manifestaciones más destacadas de la evolución del Derecho administrativo de nuestros días: su apuesta por la interacción con los ciudadanos que demandan, cada vez más, un papel activo y mayor participación en la planificación, la ejecución y la evaluación de las políticas públicas.

En este sentido, se pone de manifiesto cómo el Movimiento Cooperativo, basado en los valores de solidaridad, democracia, equidad, igualdad, autoayuda y auto-responsabilidad, ha destacado desde su origen por su compromiso social y por su contribución a la promoción del desarrollo del interés general, de tal forma y manera que todas aquellas sociedades cooperativas que integren en su objeto social como fines prioritarios de su actuación la asistencia socio-sanitaria, la educación, la vivienda, la protección y defensa del medio ambiente, el fomento de la economía social y la promoción y protección de la paz social y la ciudadanía, entre otros, participan y trabajan activa y efectivamente por y para la prestación de servicios de interés general.

Palabras clave: Participación y gestión democrática; Gestión pública; Planificación participativa; Coordinación; Tercer Sector; Cooperativas de utilidad pública; Cooperativas de iniciativa social; Servicios Públicos; Interés general.

\footnotetext{
1 Profesora de Derecho Administrativo de la Universidad de Deusto. Dirección de correo electrónico: vegamaria.arnaez@deusto.es
}

REVESCO No 116 - Tercer Cuatrimestre 2014 - ISSN: 1885-8031 - www.ucm.es/info/revesco

http://dx.doi.org/10.5209/rev_REVE.2014.v116.46578

Fecha de recepción: 27/05/2014

Fecha de aceptación: 24/07/2014 
Claves Econlit: K00, K10; K32

\title{
THE COOPERATIVE SOCIETIES OF PARTICIPATION IN PUBLIC SERVICES. THE COURSE OF THE PUBLIC UTILITY COOPERATIVE IN THE AUTONOMOUS REGION OF THE BASQUE COUNTRY
}

\begin{abstract}
In this paper one of the most outstanding expressions of the evolution of administrative law today addresses : its commitment to interaction with citizens demanding increasingly a more active role and participation in the planning, implementation and evaluation of public policy.

In this sense, it highlights how the cooperative movement, based on the values of solidarity, democracy, equity, equality, self-help and self-responsibility, stressed from the outset with its social commitment and his contribution to the promotion of development the general interest, in such form and manner as all those cooperative societies to integrate in its objects as priority action the purposes of socio- health care, education, housing, protection and defense of the environment, promoting social economy and the promotion and protection of social peace and citizenship, among others, and participate actively and effectively working for and the provision of services of general interest.
\end{abstract}

Keywords: Participation and democratic governance; Governance; Participatory planning; coordination; Third Sector; Cooperative public utility; Social initiative cooperatives; Utilities; General interest.

\section{INTRODUCCIÓN}

A lo largo de su evolución, el derecho administrativo se ha configurado como el sector del ordenamiento jurídico que tiene por objeto la atribución de diversas potestades y prerrogativas a las Administraciones Públicas, al amparo de su función o misión de servicio a la garantía y la realización de los intereses generales.

De la misma manera, y como contrapeso de las potestades de las Administraciones Públicas, el ordenamiento jurídico administrativo ha reconocido y atribuido un conjunto de garantías a los ciudadanos, las cuales, con el paso del tiempo, han crecido en importancia 
tanto cuantitativa como cualitativa, como resortes para hacer frente a los poderes exorbitantes que implica el ejercicio de las funciones públicas.

En este sentido, se puede definir el derecho administrativo como un derecho de prerrogativas y de garantías en el que el ejercicio de las potestades administrativas está sometido a una sucesión de principios y exigencias que tienen por objeto asegurar la actuación objetiva de los poderes públicos en el ejercicio de sus funciones y competencias, siempre al servicio del interés general.

Sin embargo, y aún cuando cualquier manifestación de las actuaciones de los poderes públicos es el resultado de un previo procedimiento administrativo concebido como una garantía para los administrados, lo cierto es que su tramitación evidencia una ralentización en la gestión de los intereses generales y en la prestación de los servicios públicos que lleva a cuestionar su virtualidad como garantía de los intereses de los ciudadanos.

De este modo, lo que el ordenamiento jurídico ha previsto y configurado como una garantía para los ciudadanos se ha convertido en una auténtica traba que dificulta la gestión de los servicios públicos en los términos y con la diligencia y eficacia que son deseables para dar respuesta a las demandas y necesidades sociales más acuciantes.

Es por ello por lo que ha surgido el fenómeno de la huída del derecho administrativo, como reacción a esta situación mediante la creación de una ficción jurídica consistente en la externalización de la gestión de los servicios públicos a través de personas jurídicas de base privada, bajo la forma jurídica de sociedades mercantiles (Gamero Casado y Fernández Ramos, 2010), en cuanto instituciones sujetas a un régimen jurídico organizativo y de funcionamiento propio y particular como es el de las Sociedades Cooperativas, entre otras.

\section{ALGUNAS CONSIDERACIONES SOBRE EL TERCER SECTOR}

\subsection{Delimitación conceptual}

Se puede definir el Tercer Sector como el espacio intermedio entre el sector público y el sector privado capitalista, compuesto por una diversidad de entidades y organizaciones que trabajan y desarrollan su actividad en un contexto especialmente cambiante, haciéndose cargo de los servicios tradicionalmente prestados en exclusiva por las Administraciones Públicas. 
En relación con este concepto, debe ponerse de manifiesto que, aún no existiendo unanimidad ni consenso sobre su definición, se trata de un término aglutinador de las instituciones privadas no lucrativas como alternativa tanto al mundo empresarial como del Estado proveedor de bienes y servicios públicos y de interés general.

Tradicionalmente, el estudio del tercer sector se ha abordado desde el punto de vista de la transición y evolución de los sujetos económicos hacía la incorporación de valores tales como la mutualidad económica, la gratuidad, la ausencia de intereses particulares y el ánimo de lucro.

En tal sentido, se distinguen dos planteamientos o enfoques para su estudio: el de las organizaciones no lucrativas y el de la llamada economía social.

En cuanto se refiere a las organizaciones sin ánimo de lucro, forman parte del tercer sector aquellas entidades de naturaleza privada, dotadas de personalidad jurídica propia y que estén formalmente organizadas, con una estructura interna y estabilidad en cuanto a desarrollo de actividades y objetivos no lucrativos y de interés general.

Según este concepto, formarían parte del tercer sector un amplio número de organizaciones, tales como las asociaciones comerciales y profesionales, las organizaciones benéficas tradicionales, las dedicadas al culto o a cuestiones religiosas, las conocidas popularmente como organizaciones no gubernamentales, las organizaciones de desarrollo popular y los movimientos sociales organizados.

Por otra parte, atendiendo al análisis del tercer sector desde el enfoque de la economía social y la responsabilidad social corporativa, se le puede definir como el espacio intermedio que existe entre la gestión y la prestación pública de los servicios sociales y las sociedades mercantiles.

Se trata de un concepto que se utiliza, por lo tanto, como elemento aglutinador de las instituciones privadas no lucrativas, en cuanto alternativa al mundo de la empresa y al Estado, a través de sus poderes públicos, en cuanto proveedores de bienes y de servicios.

En este sentido, el tercer sector está formado por un conjunto de organizaciones de base privada y de participación voluntaria, dotadas de personalidad jurídica propia, con capacidad de autogobierno que están formalmente organizadas y que no tienen ánimo de lucro, o lo que es lo mismo, no aspiran al reparto entre sus miembros de los beneficios 
generados por su actividad y que tienen capacidad para autogobernarse y gestionarse de forma independiente.

Dentro de este concepto, destacan en su núcleo central la sociedades cooperativas, las mutualidades, las sociedades laborales, las asociaciones y las fundaciones, en cuanto empresas privadas caracterizadas por la primacía de las personas y de su objeto social frente al capital, de adhesión voluntaria y abierta, en las que los intereses de sus miembros y de sus usuarios, en cuanto a destinatarios o clientes de los bienes y servicios que producen, concurren con el interés general de todos los ciudadanos, al mismo tiempo que se trata de entidades autónomas e independiente respecto de los poderes públicos, que trabajan en defensa de la aplicación y realización de los principios de solidaridad y responsabilidad, mediante la aplicación o asignación de los excedentes de su actividad a fines sociales tales como la creación de empleo, el fomento de nuevas actividades empresariales, el retorno de capitales invertidos y el servicio a la comunidad, entre otros (Salas, 2009).

Desde un punto de vista científico, el reconocimiento del tercer sector como objeto de estudio doctrina tiene su origen en la década de los años sesenta, en un contexto caracterizado por la crisis del modelo económico de la sociedad industrial, al que se intenta dar respuesta mediante la definición de formas alternativas de organizar las relaciones socioeconómicas con las que superar los modelos preexistentes.

Desde un punto de vista histórico, es a mediados de los años sesenta, concretamente con ocasión de la promulgación y entrada en vigor de la Ley de Asociaciones en el año 1964, cuando tiene lugar el surgimiento de numerosas organizaciones preocupadas por trabajar en pro del bienestar social y del fomento de la participación ciudadana en un espacio donde la acción de los poderes públicos aún no llegaba, o no lo hacía de manera suficiente. Sin embargo, habrá que esperar hasta finales de los años ochenta y principios de los noventa para asistir a la consolidación del tercer sector, como consecuencia del crecimiento cuantitativo y cualitativo de las demandas sociales. A continuación, durante la década de los noventa, el tercer sector vivió un momento de crecimiento y expansión como consecuencia de la consolidación del Estado del Bienestar en el que, aunque la presencia del sector público iba creciendo, lo hacía a una velocidad menor a la del crecimiento de las demandas y las necesidades sociales. 
La fundamentación del tercer sector tiene su origen, por tanto, en el papel y en las funciones que viene desarrollando en la sociedad. Ello, toda vez que, a diferencia de lo que ocurre con las empresas con fines lucrativos, las entidades que trabajan en este sector actúan satisfaciendo fines intereses generales, dicho en otras palabras, satisfaciendo demandas que no se expresan en términos económicos o monetarios.

En la actualidad, en el contexto de crisis económica y social en el que nos vemos inmersos, y en un momento en el que se cuestiona desde todos los puntos de vista el papel del Estado en la planificación y en la ejecución de las políticas públicas, las Administraciones reclaman, cada vez más, el auxilio, la intervención y la colaboración activa del denominado tercer sector como agente de innovación que trabaja para la satisfacción eficaz y eficiente de las demandas sociales.

Asistimos, en definitiva, a un momento de impulso y fomento del papel del tercer sector y sus organizaciones en el diseño, la planificación, la ejecución y la evaluación de las políticas y de los servicios públicos, en colaboración con la actividad que en tales materias desarrollan las Administraciones Públicas.

Ello, como consecuencia de la reestructuración del Estado del bienestar en la que el tercer sector y las entidades que lo integran completan con su actividad la función atribuida a los poderes públicos de satisfacción de las demandas y necesidades sociales, en contribución tanto a la mejora de las condiciones de vida de los ciudadanos como a la búsqueda de mayores cotas de bienestar social.

\subsection{Características básicas de las entidades que integran el tercer sector}

Las diversas entidades que integran el tercer sector, con independencia de cuál sea su concreta naturaleza o personificación jurídica, forman parte de la denominada economía social, entendida como un conjunto de organizaciones que, dotadas de personalidad jurídica propia, representan el protagonismo creciente de la participación ciudadana y de la sociedad civil en la tarea de atención y satisfacción de las necesidades sociales más acuciantes, al margen tanto de las opciones políticas como de los intereses económicos privados.

Se trata de un conjunto de organizaciones que trabajan por y para la prestación de servicios relacionados directa y personalmente con sus beneficiarios, realizando tareas de prestación, asistencia, garantía y promoción de los valores sociales como cauce 
institucionalizado para el ejercicio de la solidaridad voluntaria de muchos ciudadanos (Jiménez Escobar y Morales Gutiérrez, 2006).

En definitiva, el espacio social del denominado tercer sector está representado por un conjunto de entidades no lucrativas que actúan y trabajan como mediadoras entre los individuos en su esfera privada y la complejidad del sector público, con el fin de aportar a la sociedad valores y servicios distintos, y al mismo tiempo complementarios, a los que aportan las Administraciones Públicas por una parte y las sociedades mercantiles, por otra (Jiménez Escobar y Morales Gutiérrez, 2006).

Partiendo de tales consideraciones, se pueden distinguir como rasgos básicos y esenciales de las entidades que componen el tercer sector, las cuatro características siguientes: su organización formal, su naturaleza privada, su carácter participativo y de adhesión voluntaria y su finalidad solidaria.

\section{a) Organización formal}

El carácter formal de las entidades del tercer sector se concreta en la necesaria existencia en las mismas de unos órganos de gobierno, una división y organización del trabajo y determinados sistemas o procedimientos de planificación y de coordinación de la totalidad de su ámbito de actuación. Y ello, mediante la dotación de una estructura interna determinada y estable, en definitiva, mediante el reconocimiento de su personalidad jurídica y capacidad de obrar plenas.

\section{b) Naturaleza jurídica privada}

Se trata de organizaciones creadas y compuestas por sujetos privados y que, por lo tanto, se rigen por las normas propias del derecho privado en cuanto a su organización, estructura interna y funcionamiento.

Debe significarse a tal efecto, su carácter independiente y separado, estructural y jurídicamente, de las Administraciones Públicas, aún cuando realicen actividades de interés general. 


\section{c) Carácter participativo}

La participación voluntaria de sus miembros es un rasgo característico esencial de las entidades y organizaciones que integran el tercer sector. Esta característica se pone de manifiesto mediante el trabajo voluntario de las personas que las componen, su gestión abierta y la organización democrática de su actividad, desde su base hasta los órganos de gobierno.

Este carácter participativo evidencia, asimismo, la conjunción de los intereses de la organización, los de sus miembros y usuarios con el interés general de todos los ciudadanos, así como la defensa y el trabajo por la realización de los principios de solidaridad y responsabilidad.

Y ello es así, en la medida en que se trata de entidades de naturaleza privada que se han creado con la finalidad de satisfacer las necesidades de sus socios a través del mercado, produciendo bienes y servicios, asegurando o financiando y en las que la distribución del beneficio y la toma de decisiones no están ligadas directamente al capital aportado inicialmente, sino que en ellas cada uno de sus miembros representa a un voto, con independencia de las aportaciones efectuadas para su incorporación.

\section{d) Finalidad misionera y adhesión voluntaria}

Otra de las características esenciales de las entidades que integran el tercer sector es su misión, o ideario propio que está en el origen de la organización desde el momento de su constitución como tal y que incorpora postulados de todo tipo: axiológicos, ideológicos y religiosos.

Pues bien, es precisamente esta característica la que define la esencia y la razón de la propia existencia de estas entidades, en cuanto elemento aglutinante y diferenciador que permite que sus miembros trabajen y se impliquen en su gestión al margen de criterios económicos o remuneratorios. Se puede afirmar que, lo que, en definitiva, identifica y determina la esencia de estas entidades es, en palabras del profesor Ruíz Olabuénaga (2006: 13) “[...] su capacidad para canalizar la dinámica de la solidaridad voluntaria [...]”. 


\subsection{Clasificación de las entidades del tercer sector}

El carácter multidisciplinar y pluridimensional del tercer sector se pone asimismo de manifiesto en la diversificación de las entidades que lo integran, como un cuerpo formalmente organizado de personas jurídicas de diversos tipos y naturalezas.

Una visión completa del sector no lucrativo actual comprende, siguiendo al profesor Ruíz Olabuénaga (2006), los siguientes tipos de entidades u organizaciones: las organizaciones no lucrativas de acción social, las organizaciones no gubernamentales para el desarrollo, las empresas de inserción social, las fundaciones y asociaciones declaradas de utilidad pública y las cooperativas de utilidad pública e iniciativa social.

Analizamos, a continuación y brevemente, los rasgos definitorios de cada una de estas entidades en general, para centrarnos después en el régimen jurídico propio de las cooperativas de utilidad pública e iniciativa social.

\section{a) Las organizaciones no lucrativas de acción social}

Las organizaciones no lucrativas de acción social se caracterizan esencialmente por su diversidad, en múltiples aspectos: en sus objetivos o finalidades, en su dimensión, en su estilo de gestión y en sus fuentes de financiación, entre otros.

Ello se debe a que se trata de entidades que realizan actividades heterogéneas y entre sí mismas diferentes, y que están presentes en todos los ámbitos de actuación tales como las asociaciones de determinados colectivos sociales, las que trabajan en defensa del medio ambiente, las que promueven valores culturales, de acción social, de cooperación al desarrollo, de acogida a inmigrantes, de atención a personas dependientes y discapacitadas.

\section{b) Las organizaciones no gubernamentales de cooperación al desarrollo}

La Ley de Cooperación Internacional para el desarrollo de 7 de julio de 1998, en su artículo 32 define a las organizaciones no gubernamentales de cooperación al desarrollo como "aquellas entidades de derecho privado, legalmente constituidas y sin ánimo de lucro, que tengan entre sus fines o como objetivo expreso, según sus propios Estatutos, la realización de actividades relacionadas con los principios y objetivos de la cooperación internacional para el desarrollo". 


\section{c) Las empresas de inserción}

Las empresas de inserción se caracterizan porque su constitución responde a la finalidad de facilitar y favorecer la inserción social y laboral de los colectivos de personas que tienen dificultades para integrarse en el mercado laboral. Desde un punto de vista funcional, estas empresas tienen un funcionamiento similar al de cualquier otra mercantil: venden los bienes y servicios que producen y contratan a sus trabajadores según establezca el convenio del sector correspondiente a su actividad.

Lo que diferencia, singulariza y cualifica a las empresas de inserción es el hecho de que ocupan la mayor parte de los puestos de su plantilla con personas pertenecientes a colectivos con problemas y dificultades para su inserción en el mercado laboral. La finalidad y el objetivo de estas empresas consiste en que, tras un periodo determinado de aprendizaje en un puesto de trabajo real, las personas en proceso de inserción puedan acreditar su formación y capacitación para acceder a un puesto de trabajo "normalizado".

\section{d) Las fundaciones y asociaciones}

Las fundaciones son un tipo de organización que tienen por finalidad la gestión de un determinado patrimonio económico destinado a la satisfacción de fines no lucrativos y de interés general, que se caracterizan como instituciones ajenas, tanto a las Administraciones Públicas, como a los intereses económicos del mercado.

Junto con las fundaciones, destacan asimismo las asociaciones de utilidad pública como forma jurídica que adoptan las organizaciones sin ánimo de lucro para adquirir su personalidad jurídica y plena capacidad de obrar. Participan de tal naturaleza jurídica asociativa todas las agrupaciones de personas que, dotadas de una estructura organizativa estable de base democrática e independiente del Estado, de los poderes públicos y del sector económico privado, se relacionan voluntariamente con el compromiso y la finalidad de llevar a cabo una actividad colectiva estable, sin ánimo de lucro.

El rasgo esencial y distintivo de las asociaciones de utilidad pública es su capacidad como organizaciones que permiten a sus miembros reconocerse en sus convicciones, perseguir activamente sus ideales, cumplir tareas útiles, encontrar su ubicación en la sociedad, hacerse oír, ejercer algún tipo de influencia, provocar cambios sociales y contribuir a la preservación de la diversidad cultural. 


\section{e) Las cooperativas de utilidad pública e iniciativa social}

Las cooperativas de utilidad pública son aquellas sociedades cooperativas que, con su actuación y funcionamiento, contribuyen a la realización de fines de interés general, a su promoción y protección efectiva en sectores tan transcendentes como la industria, la enseñanza, la vivienda y la asistencia, entre otros (Aguilar Rubio-Vargas Vasserot, 2012; Vargas Vasserot, 2012).

En este sentido, debe ponerse de manifiesto la importancia del reconocimiento de la condición de utilidad pública para una sociedad cooperativa en cuanto se refiere a sus potencialidades de crecimiento y desarrollo, el acceso a las ayudad y protección de las entidades públicas, así como el reconocimiento del servicio que presta el movimiento cooperativista no sólo a sus asociados, sino también al conjunto de la sociedad en general.

Las cooperativas de iniciativa social, por su parte, son aquellas que, sin ánimo de lucro tienen por objeto social tanto la prestación de servicios asistenciales mediante la realización de actividades sanitarias, educativas, culturales $\mathrm{u}$ otras de naturaleza social, como el desarrollo de cualquier actividad económica que tenga por finalidad la integración laboral de personas en riesgo de exclusión y con dificultades para ser absorbidas por el mercado laboral.

\section{LA EXTERNALIZACIÓN DE LA ACTUACIÓN DE LAS ADMINISTRACIONES PÚBLICAS}

\subsection{Significado $\mathrm{y}$ alcance}

En la actualidad, la simplificación o desburocratización de la organización y del funcionamiento de las Administraciones Públicas se reconoce como uno de los retos más importantes y el objetivo más inmediato del derecho administrativo, esencial para la construcción de un nuevo modelo de Administración Pública que garantice el servicio objetivo a los intereses generales y la realización efectiva, entendida como eficiente y eficaz, de los servicios públicos, acorde con los principios constitucionales de la organización y de la actuación administrativas proclamados en el artículo 103 de la Constitución Española de 1978 (Palomar Olmeda, 2010).

En este sentido, merecen significarse las reflexiones del profesor Sebastián MartínRetortillo Baquer (1998:7) calificando la simplificación administrativa como una necesidad inmediata de las Administraciones Públicas que "[...] se enuncia siempre con un significado 
dinámico y operativo; en definitiva, como tarea a realizar que, según se verá, se proyecta en ámbitos muy distintos. En todo caso, y como punto de partida, parece obligado reconocer la necesidad de llevarla a cabo, es algo que no cabe cuestionar, tampoco que haya que hacerlo en términos rigurosos y que no admiten demora [...]".

Así pues, el fenómeno de la externalización de la actuación administrativa se configura en el derecho administrativo actual como una tendencia imparable de transformación de las Administraciones Públicas que, impulsada por las corrientes doctrinales de la denominada Nueva Gestión Pública, facilita y favorece la incorporación de los conocimientos técnicos, así como las destrezas y habilidades materiales imprescindibles para garantizar una prestación eficaz y eficiente de los servicios públicos.

En definitiva, se puede afirmar que la gestión de los servicios públicos mediante personas jurídicas privadas se ha convertido en uno de los elementos claves de la transformación de la organización y del funcionamiento de las Administraciones Públicas de nuestros días, tendente a materializar y consagrar la realización del principio de eficacia de la actuación administrativa (Sosa Wagner, 2002).

\subsection{La participación del cooperativismo en la prestación de servicios de interés general}

En el contexto actual de una economía global en el que nos vemos inmersos, la crisis financiera y económica internacional que nos afecta exige que tanto las Administraciones y demás entidades del sector público como los agentes económicos privados aúnen sus esfuerzos en torno a la recuperación económica y para la consolidación de los aspectos más sólidos y estables de nuestro modelo productivo (García Ruiz, 2013).

En este sentido, el Preámbulo de la Ley 2/2011, de 4 de marzo, de Economía Sostenible (B.O.E. núm. 55, de 5 de marzo), proclamó la necesidad de impulsar la eficiencia especialmente en el ámbito de la contratación pública y la colaboración entre el sector público y privado como " [...] elementos fundamentales de relación entre la Administración Pública y el tejido empresarial y, a la vez, como ámbitos en los que debe reforzarse la vinculación a parámetros de sostenibilidad económica [...]".

Desde los primeros años del siglo XXI, vivimos inmersos en un entorno cada vez más cambiante, en el que se vienen sucediendo importantes transformaciones económicas, sociales y también políticas, que llevan implícitas una necesidad inminente y creciente de 
reconfiguración de las Administraciones Públicas, de su organización y de su funcionamiento (Mir Puig, 2004).

En este sentido, existe en la actualidad una estrategia clara, a nivel internacional, europeo y nacional, que trabaja por la innovación de las Administraciones Públicas como elemento clave para potenciar su competitividad, eficacia y eficiencia y que apuesta por la interacción entre los poderes públicos y los ciudadanos que demandan, cada vez más, un papel activo y una mayor participación en la planificación, la ejecución y la evaluación de las políticas públicas y, en definitiva, en la gestión de los servicios de interés general.

Como ejemplo de participación y gestión democrática, destaca el fenómeno cooperativista, basado en los valores de solidaridad, democracia, igualdad, equidad, autoayuda y auto-responsabilidad, hasta el punto de poderse afirmar que lo que singulariza a las entidades cooperativas no es su objeto social o la concreta actividad que desarrollan, sino su esencia y principios rectores básicos. Concretamente, los siguientes: la adhesión voluntaria y abierta de sus miembros, su gestión democrática y la participación económica de sus socios, su autonomía e independencia, la educación, formación e información y, finalmente, la intercooperación, o colaboración entre cooperativas, junto con el interés por la comunidad que les sirve de base (Gadea Soler, 2009).

Una sociedad cooperativa se puede definir, por lo tanto, como una empresa de participación. Se trata de una fórmula organizativa que tiene como rasgo diferencial la participación democrática y económica de sus miembros, cuyo estudio y análisis en profundidad permite explicar muchos otros fenómenos participativos (Coque Martínez, 2005:18-21).

Debe significarse, por tanto, el protagonismo o, cuando menos, la creciente relevancia de las sociedades cooperativas en el ámbito de la actividad administrativa prestacional derivada de sus vocación social y comunitaria. En palabras de Argudo Périz (2007:182), en cuanto a la participación en la prestación de servicios públicos "[...] La vocación social comunitaria de la economía social y el desarrollo del cooperativismo en el sector servicios, determina necesariamente una confluencia en el campo de los servicios a las personas y a la comunidad $[\ldots] "$.

En este sentido, el presente estudio propone una aproximación al significado y alcance de la participación de las sociedades cooperativas en la prestación de los servicios de interés 
general, como expresión del cambio de rol de los ciudadanos en su relación con los poderes públicos; uno ciudadanos, en definitiva, cada vez más exigentes a la hora de conocer, influir y formar parte de cuantas decisiones afectan al funcionamiento de unos servicios públicos a cuyo mantenimiento contribuyen con el cumplimiento de sus obligaciones tributarias.

\section{LA PARTICIPACIÓN EN EL DERECHO ADMINISTRATIVO ESPAÑOL}

\subsection{Significado y alcance}

El concepto de participación ciudadana tiene diversos significados según cuál sea el concreto ámbito de la realidad social, económica, política y cultural en la que se pretenda implantar. En algunos casos, el hecho de que se potencie formalmente el desarrollo de instrumentos y procesos participativos revela la inexistencia, o cuando menos la inoperancia, de las instituciones públicas a tal efecto.

En otros casos, sin embargo, se articulan procedimientos e instrumentos de participación orientados, de facto, a ser utilizados únicamente por determinados grupos de poder, culpando a la generalidad de los ciudadanos de la debilidad democrática de las políticas públicas, consecuencia de su dejadez o desidia al no participar suficientemente en la vida política o social (Arenilla Sáez, 2011).

La importancia de la participación en el derecho administrativo ya fue puesta de manifiesto por Foshoff (1967:21) en su formulación de la denominada Administración prestacional, hacía la que ha ido evolucionando. En palabras de este autor "[...] la Administración aportadora de prestaciones se basa en la participación. El sentido del concepto de la procura existencial estriba en otorgar la protección del Derecho púbico a esta participación [...]. El concepto de procura existencial sirve en primera línea para asegurar la participación del individuo en las prestaciones de la Administración [...]”.

Ahora bien, ¿qué trascendencia jurídica tiene la afirmación de la importancia de la participación de los ciudadanos en las políticas públicas? Pues bien, a nuestro entender, las tres consecuencias jurídicas siguientes:

En primer lugar, la de garantizar la intervención de los particulares, así como de diferentes colectivos de profesionales y peritos especializados en los diferentes ámbitos de actuación pública, para dar cumplimiento efectivo a la previsión del artículo 9.2 de la Constitución Española en el que "[...] facilitar la participación de todos los ciudadanos en la 
vida política, económica, cultural y social [...]" se define como una función de los poderes públicos.

En este sentido, nos adherimos a las reflexiones de Delgado Barrio (1993:2321) en cuanto afirma que "[...] el artículo 9.2 es el fundamento genérico sobre el que la Jurisprudencia viene construyendo el principio de participación [...]. Ciertamente, no existe hoy en nuestra sociedad un espíritu participativo pero corresponde a los poderes públicos [...], a la Administración, utilizar al máximo las posibilidades que el ordenamiento jurídico ofrece a los ciudadanos para participar”.

En segundo lugar, la de afianzar y consolidar la realización del principio democrático mediante la previsión de cauces de participación obligatorios en los procesos de redacción, aprobación, ejecución y evaluación de las políticas públicas, al menos en cuanto se refiera al control de la discrecionalidad administrativa (De la Cruz Ferrer, 1992; Alberti Rovira, 1988; Garcés Sanagustín, 1996; Martín-Retortillo Baquer, 1992).

En tercer y último lugar, la posibilidad de condicionar la actuación de los poderes públicos, pudiendo llegar incluso a hacerles cambiar o, al menos, reconsiderar, sus criterios de actuación (Dromi, 1983:155).

En definitiva, y desde la perspectiva del derecho administrativo español, se puede calificar la participación ciudadana como la garantía última de la representación de los diferentes intereses, públicos o privados, implicados en la gestión de los servicios públicos (Garcés Sanagustín, 1986).

En palabras de Ander-Egg (1978:141) “[...] participar es tomar parte en todo aquello en lo que uno está implicado; dialogar es contar con la opinión de los otros y saber enriquecerse con las diferencias [...]".

En este sentido, Martín Rebollo (1984:36) ha afirmado que “[...] la idea de participación conecta con el acercamiento entre el Estado y la sociedad [...] y supone una modesta vía de superación del individualismo que ha impregnado el Derecho administrativo desde sus mismos orígenes históricos [...]. La introducción de técnicas de participación ciudadana en los asuntos allí donde esta participación sea posible y deseable, no para legitimar a la Administración sino como vía de integración social y de acercamiento de los ciudadanos. Las fórmulas participativas, que suelen ser más viables en las Administraciones 
menores, encuentran su justificación en la adopción de opciones discutibles de trascendencia, en la valoración de la oportunidad de algunas decisiones generales, en el diseño de modelos urbanos, por poner algunos ejemplos [...]".

Y ello, siempre con el propósito de construir una Administración Púbica más próxima a los administrados y a sus necesidades, de tal forma que se asegure la salvaguarda de sus derechos e intereses legítimos y, al mismo tiempo, una mejor y más efectiva prestación de los servicios de interés general.

\subsection{La participación de los ciudadanos en la gestión pública}

Tal y como se ha puesto antecedentemente de manifiesto, es destacable la apuesta del derecho administrativo actual por la configuración de un nuevo modelo de gestión democrática tanto de la Administración Pública, en su organización y funcionamiento, como de la protección, garantía y realización de los intereses públicos, en pro de su transformación en una realidad cada vez más abierta y accesible a los ciudadanos.

Se trata, en definitiva, de la introducción de un nuevo modelo de gestión pública que pretende la creciente implicación de los ciudadanos en la acción de gobierno mediante el refuerzo y el fomento de una ciudadanía activa, informada, participativa y corresponsable.

Destacan en este sentido, los trabajos desarrollados por las Administraciones estatal y autonómicas. Especialmente relevante es, a nuestro juicio, la línea de trabajo desarrollada por la Administración de la Comunidad Autónoma del País Vasco en su apuesta por la reforma de la Administración (véase http://www.irekia.euskadi.net/news), en la que se plantea como objetivo fundamental el fomento de la gestión coparticipada de los servicios públicos, mediante la intervención de los ciudadanos en todo el proceso de de planificación de las políticas públicas, desde el momento de su enunciado y definición hasta la evaluación de los resultados obtenidos tras su ejecución o implementación.

Se puede definir la planificación participativa como un enunciado normativo en virtud del cual se determinan las pautas y las directrices básicas que inspiran y condicionan la actuación, tanto de los poderes públicos como de los ciudadanos particulares, incluyendo las posibles relaciones que se establezcan entre ellos; pautas y directrices que se concretan e instrumentan jurídicamente a través de las determinaciones de los diferentes planes, proyectos 
y programas sectoriales que aprueben las Administraciones Públicas en cada caso competentes.

Además de las características propias de cualquiera de sus manifestaciones o expresiones, desde el punto de vista del Derecho administrativo la planificación de las políticas públicas tiene unas características propias y esenciales que la definen en su naturaleza jurídica de potestad administrativa.

En este sentido, la planificación se puede definir como una de las facultades de actuación o prerrogativas que el ordenamiento jurídico atribuye a las Administraciones Públicas, revistiéndolas de un estatus especial de imperium derivado de su misión de servicio a la protección, garantía y realización del interés general (García de Enterría, 1998).

Desde esta perspectiva, se pueden enunciar las siguientes características propias de la potestad administrativa de planificación: su normativismo, en tanto que cada una de sus manifestaciones instrumentales se establecen pautas de comportamiento y directrices de actuación orientadas a la consecución de fines u objetivos concretos cuantificable en términos de prestación de servicios de interés general y que son susceptibles de vincular tanto a los poderes públicos como a los ciudadanos; su virtualidad como cauce o instrumento de participación, tanto de los poderes públicos en los trámites de audiencia, como de los particulares en los de información pública, así como de determinados colectivos técnicos o peritos en el ámbito de la gestión pública; su instrumentalización al servicio de la ejecución de los principios constitucionales de objetividad, eficacia y coordinación de la actuación de las Administraciones y Entidades del sector público (Bermejo Vera, 1995).

Pues bien, el modelo de planificación participativa que nos ocupa tiene como punto de partida un concepto de participación ciudadana que comienza en la fase de redacción de las normas, mediante la convocatoria de jornadas de trabajo, foros y debates abiertos a la ciudadanía, que continúa en el momento del diseño y redacción de los planes concretos y de las estrategias singularizadas de la actuación pública y que culmina con el seguimiento y la evaluación de los resultados y del impacto producido por la implementación y ejecución de las diferentes políticas públicas.

En este contexto, el mundo cooperativo destaca por su capacidad para impulsar y liderar procesos de participación dirigidos a la optimización y a la prestación eficaz y eficiente de los servicios públicos o de interés general, especialmente los relacionados con el 
desarrollo local y con el impulso de la denominada economía social o tercer sector económico.

\section{LA PARTICIPACIÓN DEL COOPERATIVISMO EN LA PRESTACIÓN DE SERVICIOS DE INTERÉS PÚBLICO}

\subsection{Las sociedades cooperativas como empresas de participación}

De acuerdo con la declaración formulada en el año 1995 por la Alianza Cooperativa Internacional, el fenómeno cooperativista está basado en los valores de autoayuda, autorresponsabilidad, democracia, igualdad, equidad y solidaridad.

En la actualidad, y en nuestro contexto, se acepta mayoritariamente la definición de las sociedades cooperativas como aquellas empresas que tienen por objeto básico y prioritario la promoción de las actividades económicas y sociales de sus miembros y la satisfacción de sus necesidades, a través de su participación activa, observando y respetando los precitados principios cooperativos y atendiendo a la comunidad de su entorno que le sirve de base y sustento (Gadea Soler, 2009).

Lo que, por lo tanto, singulariza o distingue a la entidad cooperativa de otras personas jurídicas con carácter empresarial no es el tipo o la concreta actividad social que desarrollan, sino los principios inspiradores y rectores de su estructura y funcionamiento, esto es, los principios cooperativos revisados periódicamente por la ACI que se concretan en los ya referidos de: adhesión voluntaria y abierta de sus miembros, gestión democrática, participación económica de los socios, autonomía e independencia, educación, formación e información, cooperación entre cooperativas e interés por la comunidad que les sustenta y sirve de base (Gadea Soler, 2009).

Se trata, en definitiva, de sociedades integradas por personas que se asocian de forma voluntaria con el fin de desarrollar en común una o varias actividades de carácter empresarial, acogiéndose a un modelo organizativo que está al servicio de de sus miembros y cuyo principal objetivo es la promoción de sus actividades económicas y sociales, para el desarrollo de una empresa de propiedad conjunta y de gestión democrática, con plena observancia y respeto de los principios cooperativos en su estructuración y funcionamiento interno.

Es por ello, por lo que se puede afirma que, con independencia de cuál sea la actividad cooperativizada, ésta debe servir a una función social, como la promoción del interés 
socioeconómico de sus miembros, que se antepone al interés de la consecución de un concreto y determinado beneficio económico (Vargas Vasserot, 2012).

En el supuesto que nos ocupa, en relación con la prestación de servicios de interés general mediante sociedades cooperativas, destaca, por una parte, el papel desempeñado por estas entidades en tanto experiencias organizativas distinguidas por su esencia participativa y por su potencialidad como impulsoras del desarrollo local, por su intenso arraigo al terreno en el que están implantadas, por su tendencia a la creación de empleo estable, por su flexibilidad para adaptarse a los cambios y por su capacidad para integrarse en redes superiores (Coque Martínez, 2005).

Por otra parte, debe ponerse asimismo de manifiesto el impulso de las sociedades cooperativas, junto con las mutuas y otras asociaciones, a la ya citada institucionalización y configuración de la economía social o tercer sector, para cuya efectiva realización resulta imprescindible la articulación de técnicas de participación y colaboración con Administraciones y demás Entidades del sector público (Zurbano, Henry y Urzelai, 2012).

\subsection{Régimen jurídico de las cooperativas de utilidad pública e interés social como agentes de prestación de servicios de interés general}

\subsubsection{Las cooperativas de utilidad pública en el derecho administrativo español}

Tanto la Ley estatal de cooperativas como la práctica totalidad de legislación autonómica vigente regulan este tipo de cooperativas de iniciativa social bajo diferentes denominaciones. Entre otras, cooperativas "de bienestar social”, "de integración social”, "de interés social" (Arnáez Arce y Atxabal Rada, 2013).

La Ley estatal de cooperativas regula las cooperativas de iniciativa social e interés general al amparo de su calificación y denominación formal como "cooperativas sin ánimo de lucro", a las que define en su artículo 106 como aquellas que tienen por objeto social, bien la prestación de servicios asistenciales mediante la realización de actividades sanitarias, educativas, culturales u otras de naturaleza similar, o bien el desarrollo de cualquier actividad económica que tenga por finalidad la integración laboral de personas que sufran cualquier clase de exclusión social y, en general, todas aquellas que trabajan para la satisfacción de necesidades sociales que no estén siendo atendidas por el Mercado y/o por el Sector Público (Díaz de la Rosa, 2006). 
A continuación, en su Disposición Adicional Sexta, la precitada norma legal dispone que participan de la naturaleza jurídica de cooperativas sin ánimo de lucro cualquiera que tenga por objeto la gestión de servicios de interés general o de titularidad pública, así como aquellas que realizando diferentes actividades económicas se comprometen con la integración laboral en las mismas de personas que sufran cualquier clase de exclusión social.

Por lo tanto, para que una sociedad cooperativa sea calificada como "sin ánimo de lucro" es preciso que refleje en sus estatutos las cuatro determinaciones siguientes (Montero Simó, 2010)

Primera: que los resultados positivos que se produzcan en un ejercicio económico no podrán ser distribuidos entre sus socios.

Segunda: que las aportaciones de los socios, tanto las obligatorias como las voluntarias, no podrán devengar un interés superior al interés legal del dinero, sin perjuicio de la posible actualización de los mismos.

Tercera: que el desempeño de los cargos del consejo rector tendrán carácter gratuito, sin perjuicio de las compensaciones económicas procedentes de los gastos en que puedan incurrir los consejeros en el desempeño de sus funciones.

Cuarta: que las retribuciones de los socios trabajadores o, en su caso, de los socios de trabajo y de los trabajadores por cuenta ajena no podrán superar el 50\% de las retribuciones que, en función de la actividad y de la categoría profesional, establezca el convenio colectivo aplicable al personal asalariado de cada sector de actividad económica.

De acuerdo con la legislación estatal vigente, se puede concluir, por tanto, que las cooperativas sin ánimo de lucro, cuyo referente más destacado son las calificadas como de iniciativa social, no constituyen una nueva clase de cooperativas sino una especialidad o especificidad que puede adoptar cualquier tipo de cooperativa con independencia de la especialidad del objeto al que se dediquen (Argudo Périz, 207).

\subsubsection{Las cooperativas de utilidad pública en la Comunidad Autónoma del País Vasco}

La Ley 4/1993, de 24 de junio, de Cooperativas del País Vasco (B.O.P.V. núm. 135, de 19 de julio de 1993) fue la primera norma de nuestro ordenamiento jurídico que reguló el reconocimiento o la posible calificación de las sociedades cooperativas como "de utilidad 
pública", siempre que promuevan mediante su actividad el desarrollo y la realización de fines de interés general como la participación en la gestión de los servicios públicos.

A tal efecto, podemos considerar que sirven al interés general y contribuyen o participan en la prestación de los servicios públicos todas aquellas sociedades cooperativas en cuyo objeto social sean prioritarios fines tales como la asistencia social, la realización de actividades cívicas, educativas, culturales científicas y de investigación, de cooperación al desarrollo, de defensa del medio ambiente, de fomento de la economía social y de promoción y protección de la paz social (Montero Simó, 2010).

En desarrollo de las determinaciones de la Ley Vasca de Cooperativas, se aprobaron los Decretos 64/1999, de 2 de febrero y 61/2000, de 4 de abril, por los que se establece el régimen jurídico de las cooperativas de utilidad pública y de iniciativa social respectivamente, que analizamos brevemente a continuación.

\section{a) Régimen jurídico, concepto y características de las cooperativas de utilidad pública}

El punto de partida de la regulación de las cooperativas de utilidad pública en el País Vasco se encuentra en el Título III, artículo 137 de la Ley Vasca de Cooperativas, en el que se prevé tal reconocimiento o clasificación formal para todas aquellas sociedades cooperativas que, como hemos dicho, contribuyan a la promoción del interés general y a la más optima prestación de los servicios públicos.

En desarrollo de la citada previsión legislativa, se dictó el Decreto núm. 64/1999, de 2 de febrero, por el que se aprobó el Reglamento de sociedades cooperativas de utilidad pública del País Vasco, en cuyo artículo 3 se las define como "aquellas en cuyo objeto social sean primordiales los siguientes fines: asistencia social, cívicos, educativos, culturales, científicos y de investigación, deportivos, sanitarios, de cooperación para el desarrollo, defensa del medio ambiente, fomento de la economía social, fomento de la paz social y ciudadana, o cualesquiera otros fines de naturaleza análoga".

Debe significarse en este sentido, el importante papel desarrollado por el movimiento cooperativo vasco en sectores socioeconómicos tales como la industria, la enseñanza, la vivienda, la actividad asistencial y, en definitiva, su más que notable contribución a la realización de fines públicos y su participación en la gestión de servicios de interés general (Arnáez Arce y Atxabal Rada, 2013). 


\section{b) Régimen jurídico, concepto y características de las cooperativas de iniciativa social}

El régimen jurídico de las cooperativas de iniciativa social en el País Vasco está regulado en el Decreto 61/2000, de 4 de abril, de Cooperativas de iniciativa social, completado por lo dispuesto en el artículo 127 de la Ley Vasca de Cooperativas en relación con las denominadas cooperativas de "integración social”.

Pues bien, de acuerdo con lo dispuesto en el artículo 1 del precitado Decreto, las cooperativas de iniciativa social son aquellas que, sin ánimo de lucro y con independencia de su concreta clasificación, tienen por objeto social tanto la prestación de servicios asistenciales, mediante la realización de actividades sanitarias, educativas, culturales u otras de naturaleza social, o bien el desarrollo de cualquier actividad económica que tenga por finalidad la integración de personas que sufran cualquier clase de exclusión social y, en general, la satisfacción de necesidades sociales no atendidas ni por el Mercado ni por los Poderes Públicos (Arnáez Arce y Atxabal Rada, 2013).

Por lo que se refiere a la normativa aplicable, las cooperativas de iniciativa social de la Comunidad Autónoma del País Vasco se rigen por las normas propias y específicas de la concreta clase de cooperativa en la que, en cada caso, esté encuadrada la actividad de interés público o de prestación de servicios de interés general a la que se dediquen.

Finalmente, en relación con las cooperativas de iniciativa social, debe ponerse de manifiesto no sólo el gran desarrollo social y empresarial del cooperativismo vasco, sino la variedad de sus formas y ámbitos de actuación sectorial, sino su aportación a la satisfacción de necesidades sociales y colectivas mediante el desarrollo de una creciente participación en la gestión y en la prestación de servicios de interés general.

\section{A MODO DE CONCLUSIÓN}

En el contexto de un Estado social y democrático de derecho, la participación ciudadana y la transparencia de las políticas públicas se configuran como principios inherentes a la actuación de los poderes públicos, necesarios para garantizar una gestión administrativa eficiente, eficaz y capaz de responder a las expectativas y demandas de la sociedad.

Se puede afirmar, por tanto, que el Derecho administrativo de nuestros días está inmerso en un proceso de transformación de las relaciones entre los ciudadanos y los poderes 
públicos que tiene como punto de partida y de llegada la consolidación de una Administración Pública transparente en su actuación y en la gestión de los intereses públicos, desde la planificación de las políticas públicas hasta su ejecución material en los diferentes ámbitos y sectores de actuación administrativa.

De este modo, el camino hacia la simplificación y la progresiva desburocratización de la organización y de la actuación de las Administraciones Públicas se configura en la actualidad como el reto más importante y significativo del Derecho administrativo de nuestro tiempo, en un entorno cada vez más participativo en el que los ciudadanos han dejado de ser meros receptores de los servicios públicos para pasar a asumir un rol cada vez más exigente con el modo, las circunstancias y los principios gestores que utilizan las Administraciones Públicas para prestarlos.

Frente a los instrumentos y cauces tradicionales de participación ciudadana, tales como la consulta popular, la información y la audiencia pública o las iniciativas y propuestas ciudadanas, en los últimos tiempos se ha generalizado el desarrollo de procesos innovadores de planificación participativa, en coherencia con un modelo de gestión pública participativo y de proximidad a los destinatarios y usuarios de los servicios públicos.

En este contexto, el movimiento cooperativo en general y las diferentes sociedades cooperativas en particular, han asumido un papel protagonista como intermediarios e interlocutores entre los ciudadanos y las Administraciones Públicas en cuanto se refiere a la prestación de los servicios de interés general.

Y ello, por cuanto que las Administraciones Públicas necesitan, cada vez más, la cooperación y la participación activa del tercer sector como agente de innovación que trabaja para la satisfacción de necesidades sociales de tipo asistencial y que no se expresan en términos económicos o monetarios.

El movimiento cooperativo, basado en los valores de solidaridad, democracia, equidad, igualdad, autoayuda y auto-responsabilidad, ha destacado desde su origen por su compromiso social y por su contribución a la promoción del desarrollo del interés general, de tal forma y manera que se presume que contribuyen y trabajan por la prestación de servicios de interés general todas aquellas sociedades cooperativas que integren en su objeto social como fines prioritarios de su actuación la asistencia socio-sanitaria, la educación, la vivienda, 
la protección y defensa del medio ambiente, el fomento de la economía social y la promoción y protección de la paz social y la ciudadanía, entre otros.

La situación actual de crisis económica y social, en el que se pone en cuestión el funcionamiento y la validez del denominado Estado del Bienestar, las Administraciones Públicas necesitan, cada vez más, la cooperación y participación activa del tercer sector como agente de innovación que trabaja para la satisfacción eficaz y eficiente de las necesidades sociales asistenciales, que no se expresan en términos económicos o monetarios.

En este sentido, merece significares el proceso de reestructuración, reforma e innovación de las Administraciones Públicas en clave de potenciar su competitividad, eficacia y eficiencia, apuesta por la interacción con los ciudadanos, quienes demandan un papel cada vez más activo en la planificación, la ejecución y la evaluación de las políticas públicas que tienen por objeto la prestación de servicios asistenciales a la población, a las que responden de un modo especial las sociedades cooperativas denominadas de utilidad pública y de iniciativa social.

\section{BIBLIOGRAFÍA}

AGUILAR RUBIO, M y VARGAS VASSEROT, C. (2012) Las cooperativas sin ánimo de lucro en la prestación de servicios públicos. Análisis de fiscalidad, Sociedad y Utopía, núm. 40, 2012, pp. 404-435.

ARENILlA SÁEZ, M. (2011) Crisis y reforma de la Administración Pública, La Coruña, Netbiblo.

ARGUDO PÉRIZ, J.L. (2007) Las cooperativas sin ánimo de lucro: ¿vuelta a los orígenes o respuesta a las nuevas necesidades sociales, Revista Vasca de Economía Social, № 3, pp. 179-201.

ARNÁEZ ARCE, V.M. (2011) La comercialización de energía eléctrica a través de cooperativas de consumo, Boletín de la Asociación Internacional de Derecho Cooperativo, $\mathrm{N}^{\circ} 45, \mathrm{pp} .197-216$.

ARNÁEZ ARCE, V.M. (2012) La participación del cooperativismo en las políticas públicas, Boletín de la Asociación Internacional de Derecho Cooperativo, $\mathrm{N}^{\circ} 46$ pp. 185-200.

ARNÁEZ ARCE, V.M. (2013) La potestad planificadora de las Administraciones Públicas, Bilbao, Gomylex. 
ARNÁEZ ARCE, V.M. y ATXABAL RADA, A. (2014) Las cooperativas de utilidad pública e iniciativa social. Aspectos administrativos y fiscales, Boletín de la Asociación Internacional de Derecho Cooperativo, № 47, pp. 199-228.

BERMEJO VERA, J. (1995). Constitución y planificación hidrológica, Madrid, Civitas.

BERMEJO VERA, J. y FERNÁNDEZ FARRERES, G. (1982) Actuaciones Administrativas aisladas versus planificación: modelo urbanístico y protección del patrimonio históricoartístico, Cuadernos Aragoneses de Economía, № 1981/1982.

COQUE MARTÍNEZ, J. (2005) Compartir soluciones: las cooperativas como factor de desarrollo en zonas desfavorecidas, Madrid, Consejo Económico y Social.

DÍAZ DE LA ROSA, A. (2007) Las cooperativas de iniciativa social, Anuario de la Facultad de Derecho de la Universidad de La Coruña, N 11, pp. 201-210.

EMBID IRUJO, A. (1991) La planificación hidrológica: régimen jurídico, Madrid, Tecnos.

FORSHOFF; E. (1967) Sociedad industrial y Administración Pública, Madrid, Escuela Nacional de Administración Pública.

GADEA SOLER, E. (2009) Estudio sobre el concepto de cooperativas: referencia a los principios cooperativos y su discutida vigencia, JADO, Boletín de la Academia Vasca de Derecho, № 17 , pp. 165-185.

GARCÉS SANAGUSTÍN, A. (1996) Prestaciones sociales, financiación administrativa y derechos de los ciudadanos, Madrid, McGraw Hill.

GARCÍA DE ENTERRÍA, E. (1998) Democracia, jueces y control de la Administración, Madrid, Civitas, $4^{\mathrm{a}} \mathrm{ed}$.

GARCÍA MACHO, R. (2011) La transparencia en el sector público, en El derecho público de la crisis económica. Transparencia y sector público. Hacía un nuevo Derecho Administrativo, Madrid, Instituto Nacional de Administración Pública.

GARCÍA RUIZ, E. (2013) El negocio fundacional en las sociedades cooperativas de participación pública, REVESCO. Revista de Estudios Cooperativos, 2013, núm. 111, pp. 60-89.

JIMÉNEZ ESCOBAR, J. y MORALES GUTIÉRREZ, A.C. (2006) Dirección de entidades no lucrativas. Marco jurídico, análisis estratégico y gestión, Pamplona, Aranzadi, 2006.

MARTÍN REBOLLO, L. (1984) El Derecho administrativo y las relaciones entre las Administraciones Públicas y los ciudadanos. Lección de apertura del Curso académico 1984-1985, Cáceres, Universidad de Extremadura.

MARTÍN REBOLLO, L. (1983) Estado social y Administración Pública. Los postulados constitucionales de la reforma administrativa, Madrid, Civitas. 
MARTÍN- RETORTILlO BAQUER, S. (1992), en el Prólogo del libro de SÁNCHEZ BLANCO, A. El sistema económico de la Constitución (participación institucional de las Autonomías territoriales y dinámica social en la economía), Madrid, Civitas.

MARTÍN-RETORTILLO BAQUER, S. (2009) De la simplificación de la Administración Pública, Revista de Administración Pública, № 17, pp. 165-185.

MIR PUIG, O (2004). Globalización, Estado y Derecho. Las transformaciones recientes del Derecho administrativo, Madrid, Thomson-Civitas.

MOLINA APARICIO, F. (2009) Historia del Consejo Superior de Cooperativas de Euskadi, Vitoria-Gasteiz, Consejo Superior de Cooperativas de Euskadi.

MONTERO SIMÓ, M. (2010) La fiscalidad de las cooperativas sin ánimo de lucro, CIRIECEspaña. Revista de Economía Pública, Social y Cooperativa, № 69, pp. 161-190.

PALOMAR OLMEDA, A. (2010) Simplificación administrativa, en La ordenación de las actividades de servicios: comentarios a la Ley 17/2009, de 23 de noviembre, QUADRASALCEDO FERNÁNDEZ CASTILLO, T. (dir), Pamplona, Aranzadi, pp. 331-362.

RUÍZ OLABUÉNAGA, J.L. (2006) El sector no lucrativo en España. Una visión reciente, Bilbao, Fundación BBVA.

SALAS, A. (2009) El tercer sector en España, en Gestión actual de una ONG, MORO, L. (coord.), Madrid, LID editorial empresarial, pp. 29-42.

VARGAS VASSEROT, C. (2012) La organización de entidades público-privadas a través de sociedades mercantiles en El gobierno y la gestión de las entidades no lucrativas públicoprivadas, EMBID IRUJO, J.M. y EMPARANZA SOBEJANO, A. (Dirs.), Madrid, Marcial Pons, pp. 93-135.

ZURBANO, M., HENRY, G y URZELAI, A. (2012) El cuarto sector en Euskadi, Zamudio, Innobasque. 